\title{
Observing pro-environmental behavior based on consumer attitudes and norms
}

\author{
Jati Waskito', I Imronudin², and C Chuzaimah³ \\ ${ }^{1,2,3}$ Department of Management, Faculty of Economics and Business, Universitas Muhammadiyah Surakarta, Indonesia
}

\begin{abstract}
This study aims to investigate the differences in underlying psychological aspects regarding pro-environmental behavior between two distinct consumer groups: green product and non-green product consumers. Psychological aspects investigated includes cognitive attitude, affective attitude, social norm, and behavioral intention. Using survey, a total of 276 responses from Solo, Jogyakarta, and Semarang are succesfully collected. Confirmatory factor analysis was conducted to check the measurement model, while a multiple regression and MANOVA were performed to examine the proposed hypothesis. Compared to non-green product consumers, green product consumers exhibited significantly higher levels of cognitive attitude, affective attitude, social norm, personal norm, and green consumer behavior. Also cognitive, affective attitude, and personal norm predicted green consumer behavior. The limitations of this study include the self-reporting questionnare and the measurmenet of consumers' recycling intention rather than their actual behavior.
\end{abstract}

\begin{tabular}{ll}
\hline Keywords & $\begin{array}{l}\text { pro-environmental behavior; cognitive attitude; affective attitude; social norm; and } \\
\text { behavioral intention }\end{array}$
\end{tabular}

\section{INTRODUCTION}

Although consumers understand that proenvironmental behavior has significant contribution in preserving the environment, nevertheless consumers' attention and interest are in fact not always followed up in subsequent actions. In fact, 53 percent of consumers in Brazil, Canada, China, France, Germany, India, the United Kingdom, and the United States are concerned about environmental issues but are unwilling to move actively to protect the environment (Bonini et al., 2008). This difference raises the question of what factors are considered important for consumers to get them to be involved in pro-environmental behavior. This also relates to questions about how their proenvironmental behavior (e.g. buying green products), thinking and behaving proenvironmental practices (e.g. recycling activities).

Several studies have been conducted to investigate pro-environmental behavior from the perspective of impact-oriented or intentoriented behavior (Gatersleben et al. 2002; Kok et al., 2006; Park \& Ha, 2011). Impactoriented perspective defines proenvironmental behavior as "the extent to which people's consumption behavior can influence the availability of materials or energy from the environment, changing structure and dynamics the ecosystem or the biosphere itself "(Stern, 2000, p. 408). Researcher uses this view and investigates the causes of widespread environmental change, through direct community involvement (e.g. disposal of household waste, forest destruction) as well as indirect causes (e.g. international policy and national environment, commodity prices on world markets, and tax policy) (Vayda, 1988; Gatersleben et al. 2002; Kok et al., 2006).

In contrast, researchers who use intentoriented perspectives (e.g. Schultz and Oskamp, 1996; Van Lange et al., 1998; Kaiser, 1999). regard pro-environmental behavior as a result of individual decisions. This view is generally generated by examining aspects of consumer psychology with an emphasis on understanding what factors predict behavior that supports environmental conservation. Therefore, this study focuses on community trust, motives, and intentions that lead to certain behavioral targets.

Impact-oriented and intent-oriented are related to non-environmental pro-activity behavior both in the public and private spheres (Stern, 2000). Impact oriented 
behavioral perspectives emphasize on nonactivity behavior related to a person's concern for environmental sustainability shown in public spaces (e.g. being a member of environmental conservation organizations, involvement with environmental organizations, support for public policies such as higher taxes for environmental protection, and support / acceptance environmental regulation), while the intent-oriented perspective relates to individual behavior that is compatible with pro-environmental behavior.

From a behavioral perspective in the private sphere, Stern (2000) defines proenvironmental behavior as all kinds of friendly behavior and saves the use of materials or energy from the environment. Steg and Vlek (2009, p. 309) refer to proenvironmental behavior as "behavior that causes the least amount of damage to the environment, or even supports environmental preservation". Both definitions share the idea that consumer behavior protects or causes less environmental damage than using alternative products (not environmentally friendly). Pro-environmental behavior that is within the personal sphere, for example the behavior of purchasing goods / services for personal and household purposes (such as gasoline for vehicles, electricity for households), the use of items related to the environment (e.g. heating and cooling at home), waste disposal household, and green consumerism (for example buying recycled products and organic food). The terms sustainable consumption, pro-environmental behavior, environmental behavior, environmentally sustainable behavior, and environmentally friendly behavior are often used interchangeably (e.g. Thøgersen and O'lander, 2003). In this study, proenvironmental behavior refers to the purchase, use, and disposal of waste and consumer household products in ways that can preserve the environment (Stern, 2000). The two types of pro-environmental behavior that most often done by an individual / household are recycling and purchasing green products. Recycling is the performance of consumers to sort their own goods that can be re-used and avoid the disposal of consumables goods to preserve the environment.

Previous research on pro-environmental behavior has shown several different patterns. First, many researchers have identified those focused on important psychological factors that influence proenvironmental consumer behavior (e.g. de Groot and Steg, 2007; Fielding et al, 2008; Ohtomo and Hirose, 2007). Their research resulted in several degrees of consensus regarding key motivational factors (e.g. attitude and normative influences). Furthermore, many researchers have developed various scales to measure consumer perceptions and / or green consumption behaviors, such as the social responsible consumption scale (Webb et al, 2008), environmental attitudes for adolescents (Kaiser et al., 2007), and environmental concern scale (Snelgar, 2006). Although many research of proenvironmental behavioral often be conducted, empirical research that examines individual differences in key psychological factors related to behavioral responses is rarely conducted.

This study is intended to further explore the purchasing behavior of people who have begun to grow their awareness of the environment from their psychological aspects. This study tries to investigate from the psychological side of consumers themselves. The results of this study will further explain in a comprehensive and indepth manner of consumer care for the environment through the purchase of green products and recycling activities.

Specifically this study aims to answer the question 1) Are the key psychological factors (cognitive attitudes, affective attitudes, social norms, and personal norms) in proenvironmental behavior (recycling) significantly different between the two groups of consumers, namely those who shop for green products (green product purchasers and those who don't (non-green product purchasers)? 2) Are these psychological key factors positively related to intentions to proenvironmental behavior practices?

\section{LITERATURE REVIEW AND HYPOTHESES DEVELOPMENT}

\section{Determinants of pro-environmental behavior}

In previous findings, the researchers regard pro-environmental behavior both individually and in group as behavior that was motivated by the previous desired outcome (de Groot and Steg, 2007) or as pro-social behavior (Ohtomo and Hirose, 2007; Stern, 2000). Both viewpoints take a somewhat different 
approach to predict the socio-psychological motives of pro-environmental behavior (Bamberg et al., 2007): previously taken from rational theory (e.g. planned behavior theory, Fishbein and Ajzen, 1975), while the second depends on the norm activation model. Meanwhile several studies (e.g. Bamberg et al, 2007 \& Aertsens et al., 2009) chose to combine the two points of view as a better model because pro-environmental consumer behavior is based not only on attitude variables related to the expectancyvalue model / for example planned behavior theory), but also by normative beliefs that are manifested in the form of norms and social identities (Bamberg et al, 2007). This study focused on two types of attitudes (cognitive and affective attitudes) and two types of norms-based on trust (social and personal norms) (Aertsens et al., 2009) as discussed later.

First, cognitive attitude is a person's evaluation of attitudes towards a particular object (for example recycling) which comes from one's cognition / thinking (Eagly et al., 1994). Cognitive attitudes can be obtained from two components of belief. First is the probability of someone's subjective behavior that will produce a desirable behavior that can meet the expected value. In addition to cognition-based attitudes, several previous studies have shown the importance of taking a person's feelings-based evaluation of object attitudes (i.e. affective attitudes) in predicting behavior (Burns and Neisner, 2006; Hunter, 2006). Affective attitude towards recycling refers to a set of emotions in relation to the attitude of the object, namely recycling.

Second, social norms concern how other significant thoughts, one should behave that lead to certain behaviors. This concerns the perceived social pressure to perform or not perform certain behaviors and is a multiplication function of motivation to comply with social pressures and the possibility of social approval for certain behaviors (Ajzen and Madden, 1986).

Third, personal norms constitute one's personal normative beliefs and one's expectations around one's own behavior, which take self-interest and the interests of others. As an obligation to increase certain behaviors, one's personal norms become stronger (Schwartz, 1977).

Finally, recycling intentions are thought to be the next behavioral indicator in response to pro-environmental practices. The intention of recycling in this study refers to consumer commitment or willingness to be involved in recycling.

Although consumers understand that proenvironmental behavior has significant contribution in preserving the environment, nevertheless consumers' attention and interest are in fact not always followed up in subsequent actions. Increased awareness of environmental sustainability has occurred in many countries such as Brazil, Canada, China, France, Germany, India, Britain and America, but unfortunately this has not been followed up with concrete action). This difference raises the question of what factors are considered important for consumers to get them to be involved in pro-environmental behavior. This also relates to the question of how their pro-environmental behavior (purchasing green products), thinking and behaving pro-environmental practices (recycling).

Previous research on pro-environmental behavior has shown several different patterns. First, many researchers have identified those focused on important psychological factors that influence proenvironmental consumer behavior (e.g. de Groot and Steg, 2007; Fielding et al, 2008; Ohtomo and Hirose, 2007). Their research resulted in several degrees of consensus regarding key motivational factors (e.g. attitude and normative influences). Furthermore, many researchers have developed various scales to measure consumer perceptions and / or green consumption behaviors, such as the social responsible consumption scale (Webb et al, 2008), environmental attitudes for adolescents (Kaiser et al., 2007), and environmental concern scale (Snelgar, 2006). Although many and often pro-environmental behavioral studies are conducted, empirical research that examines individual differences in key psychological factors related to behavioral responses is rarely conducted.

\section{Green products and non-green product consumers}

In the setting of pro-environmental behavior, consumers can be divided into two groups with respect to their participation in consuming green products: green products and non-green product consumers. Green product consumres are those who deliberately buy recycled products and / or organic foods, while non-green products 
consumres are those who currently do not buy green products / services.

Research on pro-environmental behavior has shown that consumers exhibit different types of beliefs, attitudes, and behaviors. Overall, pro-environmental consumers, compared to apathetic consumers, tend to store higher pro-social and pro-environmental values (Stern et al., 1995), eco-centric values (Gilg et al., 2005), altruistic (attitudes prioritize the interests of others) and are more open to change (Stern et al., 1995). In addition, people who engage in broader proenvironmental behavior to preserve the environment are a consequence of their behavior (Vining and Ebreo, 1992), which in turn promotes normative belief activities, and behavioral intentions. For example, Thøgersen and Olander (2003) show that consumers with strong personal norms have a higher tendency to maintain their proenvironmental behavior than others. Based on previous research and role theory, this study predicts that, in contrast to consumers who buy traditional products and do not yet have experience or commitment to proenvironmental behavior, consumres who have experience and behave that are proenvironmental (e.g. purchasing green products) will have a degree of greater than cognitive attitudes, affective attitudes, social norms, personal norms, and greater intention to behave pro-environmental (for example recycling).

H1: There are significant differences in psychological characteristics between green product consumers and non-green products consumers. More specifically, green product consumers have stonger (a) cognitive attitudes (b) affective attitudes (c) social norms (d) personal norms towards and (e) stronger intentions to buy eco- friendly products compared to non-green product consumers.

\section{The correlation between attitudes, norms, and behavioral intentions}

The second objective of this study is to examine the relationship between these psychological factors. This research is focused on the recycling process conducted by consumers as pro-environmental behavior. Recycling behavior has received tremendous attention in recent years, from consumers, businesses and local governments, perhaps because of proven synergistic success. For example, research has shown that recycling plays a catalytic role in stimulating the participation of proenvironmental consumer behavior (Whitmarsh and O'Neill, 2010). This study will prove that recycling intentions are influenced by cognitive attitudes, affective attitudes, social norms, and personal norms.

Planned behavior theory suggests that attitude is a critical predictor of the intention to do something. The positive relationship between the two has been confirmed in various contexts of eco- friendly behavior, such as electricity and gas usage (Fujii, 2006), littering and purchasing organic products (Jackson, 2005). As such, it is assumed that this relationship will be consistent in the case of recycling. Consumer intention to recycle tends to be a function of both cognitive and affective attitudes. As for cognition based attitudes, consumers evaluate recycling based on the potential benefits or desired outcomes compared to costs. Recycling also involves emotion-based evaluation (i.e. affect-based attitude) such as altruistic behavior that is often performed such as blood donation (Rosenhan et al, 1981; Piercy and Nikala, 2009). Recycling is considered altruistic behavior (Smith et al, 1994), which is related to the welfare of others, including the environment of present and future generations. Therefore:

\section{H2. Cognitive attitude is positively related to the intention to buy green products}

\section{H3. Affective attitude is positively related to the intention to buy green products}

Researchers have emphasized the important role of norms in predicting a person's pro-environmental behavior (e.g. Ohtomo and Hirose, 2007). Based on research which states that combining social norms and personal norms can increase the explanatory power of pro-environmental consumer behavior (Aertsens et al., 2009) this research is focused on social norms and personal norms, which together influence the intention of recycling.

First, consumers tend to adhere to social norms because they fear social pressure and I or because their role models provide guidance on appropriate or beneficial behavior in society (Bamberg et al., 2007). As a result, the greater a person's social pressure to recycle, the more likely that 
person will behave as desired. Second, when personal norms of behavior are activated, it will impact on a strong sense of moral obligation to the desired behavior (Schwartz, 1977), which in turn will affect the behavior of intention. A consumer who has a strong belief that recycling is the right thing to do will strengthen his intention to recycle. Empirical evidence shows that consumers' intentions towards pro-environmental behavior depend on social norms (e.g. Hansen, 2005) as well as personal norms (Bamberg et al, 2007). Therefore:

\section{H4. Social norms are positively related to recycling intentions.}

\section{H5. Personal norms are positively related to recycling intentions.}

\section{METHODS}

The survey was conducted by going to and meeting face to face. this study used a questionnaire distributed to 300 people in three big cities in Indonesia, namely Jogyakarta, Solo and Semarang. Of 300 questioners distributed, 289 of them were returned. As much as 12 questionnaires were not processed because many items were not answered (blank). Samples were taken using a purposive sampling method, which considers the balance of their personal characteristics such as age, sex, education, occupation, and their experience in buying green products.

The definition, measurement, Cronbach apha of construction in this study are as follows; Personal norms are measured using three questions from Vining and Ebreo (1992) $(\alpha=0.924)$. Social norms (three items) $(\alpha=0.863)$, cognitive attitudes (five items) ( $\alpha=$ 0.915 ), and behavioral intention to recycle (three items) ( $\alpha=0.87$ ) were assessed using a scale from Fielding et al. (2008). Affective attitude was measured using four questions adopted from Kidwell and Jewell (2008) ( $\alpha=$ 0.894 ) and modified for this study. All questions were scored on a seven-point Likert scale $(7=$ strongly agree), except for cognitive attitudes whose items were rated on a seven-point semantic differential scale.
Respondents were grouped into green products and non-green product consumers by asking whether they were buying ecofriendly products if possible. Those who say "yes" are grouped to green products consumers, while groups of non-green products consumers answer "no".

To test the validity of each indicator questionnaire will be used factor analysis and to test the reliability, Cronbach Alpha is used. The results of the factor analysis are shown in Table 1. Data analysis consists of three stages: first, confirmatory factor analysis (CFA) to evaluate the measurement model of research variables, validity, and reliability; second, multivariate analysis of variance (MANOVA) to test $\mathrm{H} 1$ which formulates differences in psychological factors between green product and non-green product consumers; and the last, multiple regression analysis to test $\mathrm{H} 2-\mathrm{H} 5$ which predicts the relationship between cognitive and affective attitudes, social and personal norms, and recycling intentions. In addition to building the reliability of the CFA, internal consistency of the multi-item scale was assessed using Cronbach's alpha estimation.

The result of factor analysis by the principal component analysis method extracting manifest variable into four factors based on the Eigen value. The cumulative percentage level of contribution of all research factor variables was $80.491 \%$. Giving the name of each factor has been determined beforehand considering the purpose of factor analysis for this research is to make sure whether the questions raised really represent the desired construct of the variable.

\section{RESULTS AND DISCUSSION}

Respondents consisted of 152 (55.1\%) men and $124(44.9 \%)$ women, the most of them ranging from 31 to 40 years old $(40.8 \%)$. Resident domicile spread in Solo 93 people $(33.7 \%), 88(31.9 \%)$ people in Yogyakarta, and 95 people $(34.4 \%)$ in Semarang. The majority of the sample (63\%) have the intention to purchase green products or carry out environmentally friendly activities such as recycling. 
Table 1.

MANOVA

\begin{tabular}{lllll}
\hline Source & Dependent Variable & df & $\begin{array}{l}\text { Mean } \\
\text { Square }\end{array}$ & F \\
\hline Purchase & Cognitive attitudes & 1 & 451,842 & $75,598^{\star * *}$ \\
Intention & Affective attitudes & 1 & 854,839 & $98,635^{\star * *}$ \\
& Social norms & 1 & 92,985 & $21,523^{\star * *}$ \\
& Personal norms & 1 & 798,723 & $206,799^{\star * *}$ \\
\hline \multicolumn{2}{c}{${\text { Notes: }{ }^{* \star *} \text { p: } 0.00}$}
\end{tabular}

Table 2.

Regression Analyses

\begin{tabular}{lllll}
\hline & B & S.E. & t \\
\hline 1 & (Constant) &,- 294 &, 138 & $-2,133^{*}$ \\
Cognitive attitudes &, 026 &, 010 & $2,766^{* *}$ \\
Affective attitudes &, 038 &, 007 & $5,681^{\star * *}$ \\
Social norms &, 000 &, 011 & 0,015 \\
& Personal norms &, 087 &, 010 & $9,080^{\star * *}$ \\
\hline
\end{tabular}

N: $0.05 ;{ }^{\star \star} p: 0.01$

Answering the first research objective, namely whether psychological key factors (cognitive attitudes, affective attitudes, social norms, and personal norms) in proenvironmental behavior (recycling) differ significantly between the two groups of consumers, namely those who shop for green products (green product consumers) and those who don't (non-green product consumers)?" are obtained Multivariate Analysis test (MANOVA) as shown in Table 1.

The MANOVA results confirmed the existence of significant differences in cognitive attitudes ( $F=75.598 ; p=0,000)$, affective attitudes ( $F=98.635 ; p=0,000)$, social norms $(F=21.523 ; p=0,000)$, and personal norms $(F=206.799 ; p=0,000)$, between residents who care about environmental sustainability and those who are apathetic. Thus the first hypothesis $\mathrm{H}_{1}$ is supported. Pro-environmental residents have a degree of cognitive attitude $(\mathrm{H} 1 \mathrm{a})$, affective attitude $(\mathrm{H} 1 \mathrm{~b})$, social norms $(\mathrm{H} 1 \mathrm{c})$, and personal norms ( $\mathrm{H} 1 \mathrm{~d})$ that are higher than citizens who are apathetic towards the environment. This findings supports Biddle, 1986; Eagly et al., 2000; Park \& Ha, 2012 which has succeeded in classifying consumers based each with different participations in pro-environmental consumption, manifest different psychological characteristics.

Answering the second question, "Are these psychological key factors positively related to the intention to buy environmentally friendly products?" As well as testing $\mathrm{H} 2$ to $\mathrm{H} 5$, multiple regression analysis was used.

To test the second hypothesis "H2. Cognitive attitude is positively related to the intention to buy green products "by using a regression test that has a significant effect (beta $=0.026, p=0.006$ ). This shows that one's intention to buy green products is influenced by the perceptions, beliefs and stereotypes that individuals have about something. Buying green products is a representation of what individuals believe. In their minds have also been patterned about the importance of consuming green products. For example, they think that they need to start using detergent soap and other household products that have an eco-friendly label, that consuming eco-friendly products is wise, recycling is an activity that needs to be done, and buying eco- friendly products is beneficial.

To test the third hypothesis "H3. Affective attitude is positively related to the intention to buy green products "using the regression test obtained a significant effect (beta $=0.038, p=$ 0.000). This shows that one's intention to buy green products is influenced by their character and behavior such as feelings, interests, attitudes, emotions, and values.

Consumers feel happy when they can recycle the items they already use. They feel happy doing activities that support environmental preservation. Consumers who are pro-environmental also feel that the ecofriendly car program has recently become a topic that has long been discussed as a 
positive thing. They also feel satisfied by consuming rice, organic vegetables.

To test H4. "Social norms are positively related to the intention to buy environmentally friendly products" by using a regression test obtained insignificant influence (beta $=0.000$, $p=0.988)$. This shows that the intention of someone to buy green products is not at all influenced by others (although highly respected) and the pressure of the environment or the surrounding community. It could also be translated that, residents do not yet have real examples of people they admire and are proud of in terms of environmental activities. For example religious leaders, community leaders in the local area, officials, idol artists etc. that has become a trend setter not yet or not providing examples relating to environmental preservation. They rarely get advice, direction, advice, or real examples that can be copied from admirable figures.

To test H5. "Personal norms are positively related to the intention to buy eco-friendly products" using a regression test obtained a significant effect (beta $=0.087, p=0.000$ ). Pro-environmental residents feel they have a strong personal obligation to protect the environment. They are willing to re-use items such as plastic bags for shopping. Besides that guilt also arises when disposing of items that can pollute the environment, in fact the item can actually be re-used.

Among the determinants of purchasing eco-friendly products, personal norms are the highest factors $(t=9.080 ; P=0.000)$ followed by affective attitude $(t=5.681 ; p=0.000)$ and finally affective attitude $(t=2.766 ; p=0.006)$.

This finding supports previous research which found that socio-psychological characteristics would influence their commitment to the environment (Gilg et al., 2005; Stern et al., 1995; Park \& Ha, 2012). This finding yields also support for Aertsens et al. (2009) and Osterhus (1997), who showed that combining social and personal normative influences would advance existing knowledge about determinants of consumers' pro-environmental behavior.

\section{Discussion}

Consuming eco-friendly products in a sustainable manner will benefit consumers, retailers, and the environment simultaneously. Therefore it can be proven how important it is to help consumers engage in pro-environmental behavior clearly (e.g. Williams et al., 2010). To identify ways to encourage pro-environmental consumer behavior, this study has explored: how different types of consumers relate to proenvironmental behavior (green product and non-green product consumers) in their psychological aspects. Psychological factors examined in this study are cognitive attitudes, affective attitudes, social norms, personal norms, and intention to buy eco-friendly products.

Findings of this study make important theoretical contributions. First, this study adds to the external validity of role theory by showing its application in the context of proenvironmental consumer behavior (recycling) (Biddle, 1986; Eagly et al, 2000). This study proves that two groups of consumers, each with different participation in consumption and pro-environmental behavior. They also have different psychological characteristics in other proenvironmental behaviors such as recycling. More specifically, like buyers of eco-friendly products have better cognitive and affective attitudes. Pro-environmental consumers have social impulses and personal obligations, and a greater desire to buy green products than consumers who are apathetic. These results are in line with those stated by role theory, which positions that different groups of people are influenced by roles that are shown with different behaviors (Eagly et al., 2000).

Second, regarding the findings discussed earlier, this study contributes to the literature on pro-environmental consumer behavior by differentiating consumer groups through their commitment to pro-environmental practices. Buyers of green products and non-green products have different levels of attitude, perceptions, and willingness to carry out proenvironmental activities. These results imply that consumers with prior experience or who have committed to pro-environmental practices can easily support other proenvironmental disciplines by comparing with consumers without similar experience or commitment. This study also supports previous research which states that the level of consumer commitment to the environment varies depending on their socio psychological characteristics (Gilg et al., 2005).

Third, consumers' desire to consume ecofriendly products depends on their cognitive, affective, and personal norms. This result does not support the findings of Aertsen et al. (2009), which has combined personal and social norms as a strong factor influencing 
pro-environmental behavior. While in this study, only personal norms are very influential on pro-environmental behavior, but not on social norms. Probably, the respondents in this study have not found a figure that are able to influence them to care more about the environment. Likewise, the residents around them live also have not been able to provide significant pressure to them to behave in a pro-environmental manner. This means that pro-environmental behavior is still at the level of personal interests and not yet common interests (social).

In a business view, these results provide important information to retailers with very useful information such as how to use resources effectively to develop sustainability. Marketing and product development strategies that emphasize on the attributes of cognitive and affective attitudes and social and personal norms related to sustainable consumption may work to encourage consumers who have little or no interest in pro-environmental behavior to show certain behaviors. The message in advertising and product packaging can communicate well the functional benefits, emotions, needs, social values, and personal obligations for present and future generations as well as one's family and community. Such marketing campaigns and product information might be effective in encouraging awareness and attention to the environment, which in turn will encourage consumers who have a low interest in pro-environmental behavior to use pro-environmental products.

\section{CONCLUSION}

The results of this study can be concluded that, citizens who are pro-environmental have a degree of cognitive attitude $(\mathrm{H} 1 \mathrm{a})$, affective attitude $(\mathrm{H} 1 \mathrm{~b})$, social norms $(\mathrm{H} 1 \mathrm{c})$, and personal norms $(\mathrm{H} 1 \mathrm{~d})$ that are higher than residents who are apathetic towards the environment. One's intention to buy green products is influenced by perceptions, beliefs, and stereotypes that individuals have about something (H2), their character and behavior such as feelings, interests, attitudes, emotions, and values (H3). Meanwhile someone's intention to buy green products is not at all influenced by others (although highly respected) (H4). Pro-environmental residents feel they have a strong personal obligation to protect the environment (H5).
The limitation of this study is that it uses a questionnaire that was filled in by respondents themselves, where they were only asked for their activities and not on concrete actions that were pro-environmental . The data is cross section, so it has not been able to show the attitudes and behaviors and norms of respondents who are sustainable. Another weakness is the limitation of proenvironmental activities, which is the activity of buying green products and recycling. In addition, respondents were also in three cities that were close together and had more or less similar cultures.

Suggestion for future research, a direct observation study on the respondent's behavior in the long run would be more appropriate to use. Thus, the data used will be more appropriate to use time series. In the long term observation will be able to find real pro-environmental activities from residents who are not just interested in buying green products or recycling, but also other proenvironmental activities that are often carried out by the community. Then it would be better if endeavored so that respondents have diverse patterns in beliefs, attitudes, norms, roles, and behavior. So, in general has a diverse character of psychology, behavior, structure, and institutions, not grouping on one cultural root (Seock \& Lin, 2011). In addition, the model in this study explains that 51.6 percent of pro-environmental behavior is influenced by personal norms, social norms, cognitive attitudes, and affective attitudes. This shows that there are still some other psychological variables that also influence pro-environmental behavior, for example perceived behavioral control and social identity (Fielding et al, 2008).

\section{REFERENCES}

Aertsens, J., Verbeke, W., Mondelaers, K. and Huylenbroeck, G.V. (2009), "Personal determinants of organic food consumption: a review", British Food Journal, Vol. 111 No. 10, pp. 1140-67.

Ajzen, I., \& Fishbein, M. (1975), "Belief, attitude, intention, and behavior: An introduction to theory and research", 129-385, AddisonWesley, Reading, MA.

Ajzen, I. and Madden, T. (1986), "Predictions of goal-directed behaviour: attitudes, intentions and perceived behavioral control", Journal of Experimental Social Psychology, Vol. 22 No. 5, pp. 453-74. 
Bamberg, S. and Mo"ser, G. (2007), "Twenty years after Hines, Hungerford, and Tomera: a new meta-analysis of psycho-social determinants of pro-environmental behavior", Journal of Environmental Psychology, Vol. 27 No. 1, pp. 14-25.

Bamberg, S., Hunecke, M. and Blo"baum, A. (2007), "Social context, personal norms and the use of public transportatio n: two field studies", Journal of Environmental Psychology, Vol. 27 No. 3, pp. 190-203.

Biddle, BJ (1986), "Recent development in role theory", Annual Review of Sociology, Vol. 12 , pp. $67-92$.

Bonini, SMJ, Hintz, G. and Mendonca, LT (2008), "Addressing consumer concerns about climate change", McKinsey Quarterly, available at www.mckinseyquarterly.com /Strategy/Strategic Thinking/Addressing consumer concerns about climate Change 2115 (accessed 25 March 2011).

Burns, DJ and Neisner, L. (2006), "Customer satisfaction in a retail setting: the contribution of emotion", International Journal of Retail \& Distribution Management, Vol. 34 No. 1, pp. 49-66.

de Groot, J. and Steg, L. (2007), "Genera I beliefs and the theory of planned behavior: the role of environmental concerns in the TPB", Journal of Applied Social Psychology, Vol. 37 No. 8, pp. 1817-36.

Eagly, AH, Mladinic, A. and Otto, S. (1994), "Cognitive and affective bases of attitudes toward social groups and social policies", Journal of Experimental Social Psychology, Vol. 30 No. 2, pp. 113-37.

Eagly, A. H., Kulesa, P., Brannon, L. A., Shaw, K., \& Hutson -Comeaux, S. (2000). "Why counter attitudinal messages are as memorable as proattitudinal messages: The importance of active defense against attack". Personality and Social Psychology Bulletin, 26, 1392-1408.

Fielding, KS, McDonald, R. and Louis, WR (2008), "Theory of planned behaviour, identity and intentions to engage in environmental activism", Journal of Environmental Psychology, Vol. 28 No. 4, pp. 318-26.

Fujii, S. (2006), "Environmental concern, attitude toward frugality, and ease of behavior as determinants of pro-environmental behavior intention", Journal of Environmental Psychology, Vol. 26 No. 4, pp. $262-8$

Gatersleben, B., Steg, L., Vlek, C., 2002. Measurement and determinants of environmentally significant consumer behavior. Environment and Behavior 34, 335-360.
Gilg, A., Barr, S. and Ford, N. (2005), "Green consumption or sustainable lifestyles? Identifying the sustainable consumer", Futures, Vol. 37 No. 6, pp. 481-504.

Hansen, T. (2005), "Adoption of online grocery buying: a discriminant analysis", International Journal of Retail \& Distribution Management, Vol. 33 No. 2, pp. 101-21.

Hunter, GL (2006), "The role of anticipated emotion, desire, and intention in the relationship between image and shopping center visits", International Journal of Retail \& Distribution Manajemen, Vol. 34 No. 10, pp. 709-21.

Jackson, T. (2005), "Motivating sustainable consumption: a review of evidence on consumer behaviour and behavioural change". London: Sustainable Development Research Network. Available at: http://www.sdresearch.org.uk/wp-content/uploads /motivatingscfinal_000.pdf

Kaiser, FG, Oerke, B. and Bogner, FX (2007), "Behavior-based environmental attitude: Development of an instrument for adolescents", Journal of Environmental Psychology, Vol. 27 No. 3, pp. 242-51.

Kaiser, FG, Wolfing, S. and Fuhrer, U. (1999), "Environmental attitude and ecological behaviour", Journal of Environmental Psychology, Vol. 19 No. 1, pp. 1-19.

Kidwell, B. and Jewell, RD (2008), "The influence of past behavior on behavioral intent: an information processing-processing explanation", Journal of Psychology and Marketing, Vol. 25 No. 12, pp. 1151-66.

Kok, R., Benders, R.M.J., Moll, H.C., 2006. Measuring the environmental load of household consumption using some methods based on input-output energy analysis: a comparison of methods and a discussion of results. Energy Policy 34, 2744-2761.

Ohtomo, S. and Hirose, Y. (2007), "The dualprocess of reactive and inte ntional decision-making involved in eco-friendly behavior", Journal of Environmental Psychology, Vol. 27 No. 2, pp. 117-25.

Osterhus, T.L. (1997), "Pro-social consumer influence strategies: when and how do they work?", Journal of Marketing, Vol. 61 No. 4, pp. 16-29.

Piercy, NF and Nikala, L. (2009), "Corporate social responsibility: Impacts on strategic marketing and customer value", The Marketing Review, Vol. 9 No. 4, pp. 33560 
Rosenhan, D. L., Salovey, P., \& Hargis, K. (1981). The Joys of Helping. Journal Of Personality And Social Psychology, 40,899-905

Schultz, W.P., Oskamp, S., 1996. Effort as a moderator of the attitude-behaviour relationship: general environmental concern and recycling. Social PsychologyQuarterly 59, 375-383.

Schwartz, SH (1977), "Normative influences on altruism", in Berkowitz, L. (Ed.), Advances in Experimental Social Psychology, Vol. 10, Academic Press, New York, NY, pp. 222-79.

Seock, YK. and Lin, C. (2011), "Cultural influence on loyalty tendency and evaluation of retail store attributes: an analysis of Taiwanese and American consumers", International Journal of Retail \& Distribution Management, Vol. 39 No. 2, pp. 94-113.

Smith, SM, Haugtvedt, CP and Petty, RE (1994), "Attitudes and recycling: Does the measurement of affect enhance behavioral prediction?" Psychology and Marketing, Vol. 11 No. 4, pp. 359-74.

Snelgar, RS (2006), "Egoistic, altruistic and biospheric environmental concern: measurement and structure", Journal of Environmental Psychology, Vol. 26 No. 2, pp. 87-99.

Steg, L. and Vlek, C. (2009), "Encouraging proenvironmental behaviour: an integrative review and research agenda", Journal of Environmental Psychological, Vol. 29 No. 3, pp. 309-17.

Stern, PC (2000), "Toward a coherent theory of environmentally significant behavior", Journal of Social Issues, Vol. 56 No. 3, pp. 407-24.

Stern, PC, Dietz, T. and Guagnano, G. (1995), "The new ecological paradigm in socialpsychological context", Environment and Behavior, Vol. 27 No. 6, pp. 723-43.

Thøgersen, J. and O"lander, F. (2003), "Spillover of environment-friendly consumer behaviour", Journal of Environmental Psychology, Vol. 23 No. 3, pp. 225-36.

United Nations Environment Programme (UNEP) (2010), "Assessing the environmental impacts of consumption and production: priority products and materials", available at:www.unep.org/ resource panel /documents/pdf/Priority Products and Materials_Report_Full.pdf (accessed 24 February 2011).

Van Lange, P.A.M., Van Vugt, M., Meertens, R.M., Ruiter, R.A., 1998. A social dilemma analysis of commuting preferences: the roles of social value orientations and trust. Journal of Applied Social Psychology 28, 796-820

Vayda, Andrew P. (1988). "Actions and Clconsequences as objects of explanation in human ecology. Environment, Technology, and Society $51: 2-7$.

Vining, J. and Ebreo, A. (1992), "Predicting recycling behaviours from global and specific environmental attitudes and changes in recycling opportunities", Journal of Applied Social Psychology, Vol. 22 No. 20 , pp. $1580-607$

Webb, DJ, Mohr, LA and Harris, KE (2008), "A reexamination of socially responsible consumption and its measurement", Journal of Business Research, Vol. 61 No. 2, pp. 91-8.

Whitmarsh, L. and O'Neill, S. (2010), "Green identity, green living? The role of proenvironmental self-identity in determining consistency across diverse proenvironmental behaviors", Journal of Environmental Psychology, Vol. 30 No. 10, pp. 305-14.

Williams, J., Memery, J., Megicks, P. and Morrison, M. (2010), "Ethics and social responsibility in Australian grocery shopping", International Journal of Retail \& Distribution Management, Vol. 38 No. 4, pp. 297-316. 